\title{
Provenance of Zhou Dynasty bronze vessels unearthed from Zongyang County, Anhui Province, China: determined by lead isotopes and trace elements
}

\author{
Yanjie Wang ${ }^{1}$, Guofeng Wei ${ }^{1 *}$, Qiang $\mathrm{Li}^{1}$, Xiaoping Zheng ${ }^{2}$ and Danchun Wang ${ }^{3}$
}

\begin{abstract}
Thirteen Zhou Dynasty bronze vessels and two slags from Zongyang County along the north bank of the Yangtze River in Anhui were analyzed by LA-MC-ICP-MS and EDXRF. The results of lead isotope analysis showed that there were two kinds of lead materials in the Zongyang bronzes. Vessels in Class I, thought to have originated from the Wannan region were primarily used during the Western Zhou and the following Spring and Autumn period; while those in Class II, possibly from the local mines in Zongyang County, were mainly present during the Warring States period. Such a shift in the ore material sources is also revealed by the trace element analysis of the Zongyang bronzes. With reference to the relevant historical documents, we suggest that the transformation of the bronze material sources might have been associated with the changes of the political situation during the Zhou Dynasty.
\end{abstract}

Keywords: Bronze vessels, Mining and smelting, Lead isotopes, Trace elements, Provenance

\section{Introduction}

The making of bronze vessels, as one of the hallmarks of the Bronze Age in China, has long been a key issue in archaeological studies, which can provide significant insight into the cultural traditions and economic activities of ancient society. Anhui Province is situated in mideastern China and occupies a critical geographic position for understanding the exchange networks and the interactions among ancient people in different geographical regions of China. Anhui is also of interest for examining technological and cultural variation, as the region is characterized by different ecosystems and variable geomorphic environments. In addition, large numbers of archaeological sites featuring bronze vessels dating back to the Shang and Zhou Dynasties, especially the bronze mining and smelting sites, have been found across Anhui,

\footnotetext{
*Correspondence: weidun1975@126.com

1 School of History, Anhui University, Hefei 230039, China

Full list of author information is available at the end of the article
}

providing important materials for relevant archaeological and metallurgical studies.

Anhui Province's Zongyang County is located on the north bank of the Yangtze River and in the western part of the Jianghuai region that is the areas between the Yangtze River and Huaihe River. Zongyang also serves as an important bridge between the Jianghuai region and the Wannan region (a.k.a. South Anhui). In the Jianghuai region, a series of archaeological remains and cultures have been identified over a long period of time. With indepth studies of the bronze cultures in this region, it has also attracted attention to the Zongyang bronze vessels. The study of the smelting remains from the Tangjiadun site showed that the smelting process of "copper sulphide ore-copper" existed as early as the late Shang Dynasty in Zongyang [1]. However, only a few metallurgical studies have been carried out on the Zongyang bronze vessels. For example, analysis on manufacturing technology and mineral sources indicated that the Zongyang bronze vessels predating the Qin Dynasty were generally
Springer Open

(c) The Author(s) 2021. Open Access This article is licensed under a Creative Commons Attribution 4.0 International License, which permits use, sharing, adaptation, distribution and reproduction in any medium or format, as long as you give appropriate credit to the original author(s) and the source, provide a link to the Creative Commons licence, and indicate if changes were made. The images or other third party material in this article are included in the article's Creative Commons licence, unless indicated otherwise in a credit line to the material. If material is not included in the article's Creative Commons licence and your intended use is not permitted by statutory regulation or exceeds the permitted use, you will need to obtain permission directly from the copyright holder. To view a copy of this licence, visit http://creativecommons.org/licenses/by/4.0/. The Creative Commons Public Domain Dedication waiver (http://creativeco mmons.org/publicdomain/zero/1.0/) applies to the data made available in this article, unless otherwise stated in a credit line to the data. 
manufactured by casting [2], and the provenance may be related to the local mineral resources [3].

This research attempts to study the possible ore sources of 13 bronze vessels along with two slags from Zongyang using lead isotope and trace element tracing technology, which can provide new data and greater insight into the development of bronze cultures and the circulation of metal resources in this region of China.

\section{Archeological context}

The geology of Zongyang is rich in mineral resources due to its location in the middle part of a Mesozoic volcanic basin between the Tancheng-Lujiang fault zone and the fracture zone along the Yangtze River [4]. Since the 1980s, archaeologists from the Anhui Provincial Institute of Cultural Relics and Archaeology (APICRA) have conducted a series of archaeological excavations at sites within Zongyang County, including but not limited to the Tangjiadun, Xiaobeidun, and Jingbian sites [5-8], which have unearthed some pottery (Additional file 1: Table S1) and identified several ancient mining and smelting remains. Specifically, the slags, furnace walls, pottery molds, bronze vessels, and other metallurgical remains unearthed from the Tangjiadun site indicate that smelting and casting activities occurred in the Zongyang area as early as the late Shang Dynasty [8].

In 2018, our joint team of archaeologists from Anhui University and the Zongyang Museum conducted systematic archaeological surveys around the areas of Liufeng-Sangong Mountain (Fig. 1A) and the Fengsha Lake (Fig. 1B) to better understand the mining and smelting heritage in Zongyang. A total of 19 ancient copper mining and smelting sites were found, including 14 mining sites and 5 smelting sites (Fig. 1). In addition, we measured one wooden support sample from the Jingbian mining site in this region, suggesting an AMS ${ }^{14} \mathrm{C}$ date of $2260 \pm 30 \mathrm{BP}(2344-2155$ cal. BP) which was equivalent to the Eastern Zhou Dynasty and consistent with the cultural characteristics of the contemporaneous pottery fragments at the site [7]. Thus we conclude that people in the Zongyang area were engaging in copper mining and smelting activities as early as the Shang and Zhou Dynasties.

Specifically, within the Liufeng-Sangong area, our team found five new mining sites at Heyezhuang, Jiangjiawa, Dayangshan, Xiaoshuzui, and Mianjishan. At these sites, we discovered several mining pits, prospecting troughs, shafts, drifts, copper ores and ceramic fragments (Fig. 2), with no slags. In stark contrast, slags (Fig. 3) were found near the Fengsha Lake at the sites of Chuanxingniuxing, Zujiadun, Xiliusi, and Duntou, apart from the previously excavated Tangjiadun site. On this basis, we suggest that, the Liufeng-Sangong Mountain area of Zongyang once served as a mining center, while the surrounding areas of the Fengsha Lake was an important smelting center of copper ores.

In addition, the bronze vessels from Zongyang show similarities with those not only from the local regions but from the Central Plain and the states of $\mathrm{Wu}$ and Yue [9]. Combined with the mining and smelting remains discovered in this region, we suggest that Zongyang might be an important channel for cultural exchange and metal resources circulation between north and south of China.

\section{Materials and methods Samples}

In this paper, we analyzed a total of 13 bronze samples taken from the tombs of Zongyang by the Cultural Relics Management Institute of Zongyang County during the 1980s and 1990s, four of which were dated to the Western Zhou Dynasty, one to the Spring and Autumn period, and eight to the Warring States period. In addition, two slag samples from the Tangjiadun site were also measured. To identify the copper ore source of the Tangjiadun slags, we compared control groups composed of five slags from the Wannan region (four from the smelting sites of Jinshansheng, Muyushan, Wangyingshan, and Yanzimu in Tongling, and one from the Jiangmuchong smelting site in Nanling). Details of all the samples are shown in Table 1 and Fig. 4.

First, we cut the slags to appropriate sizes using a cutting machine to expose the copper prills contained within the slags of each section. After cleaning the bronze and slag samples with an ultrasonic wave cleaner, we mounted them in the epoxy resin for surface polishing in order to create a bright and pollution-free test plane. Finally, we analyzed the major elements, the trace elements, and the lead isotope ratios of all these samples.

\section{Instrument}

Main element analysis of the bronzes was conducted in the APICRA using EAGLE-III $\mu$ I-type Energy-Dispersive X-Ray Fluorescence Spectrometer (EDXRF) by American EDAX International Incorporation. The instrument is equipped with VISION32 analysis software, and its specific working conditions are as follows: the voltage of the X-ray tube is $40 \mathrm{kv}$, the current of the tube $400 \mu \mathrm{A}$, and the dead time about $30 \mathrm{~s}$. Each sample measured three valid points and each point measured for $30 \mathrm{~s}$, from which the average value for each was calculated.

Lead isotope ratios were measured using the LA-MCICP-MS at the State Key Laboratory of Continental Dynamics at Northwest University in China. The MCICP-MS system is Nu plasma II MC-ICP-MS with the latest generation of double-focusing mass spectrometers by $\mathrm{Nu}$ Instruments in Wrexham, United Kingdom. 


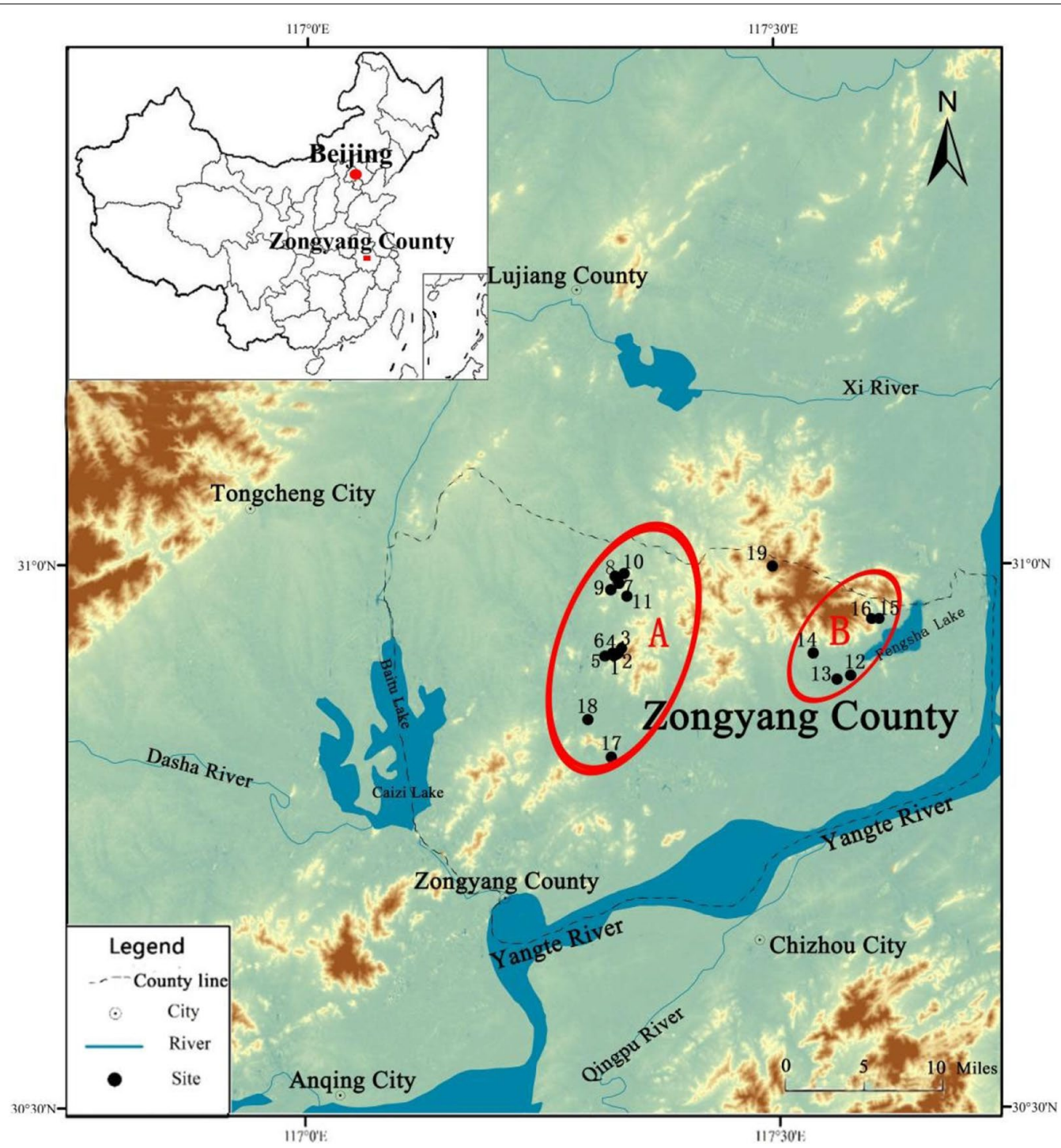

Fig. 1 Location of the mining and casting sites in Zongyang County 1. Tongkeng mining site; 2. Jiangjiawa mining site in Sunzishan; 3. Xiaoshuzui mining site; 4. Dayangshan mining site; 5 . Shadun mining site; 6 . La'edi mining site; 7. Yehezhuang mining site; 8 . Hudang mining site in Longjing; 9. Tongkuangling mining site; 10. Luohuangdou mining site; 11. Miandishan mining site; 12. Chuanxingniuxing site; 13. Zujiadun site; 14. Tangjiadun site; 15. Xiliusi site; 16. Duntou site; 17. Niutoushan mining site; 18. Bamaoshan mining site; 19. Jingbian mining site

Despite the disadvantages concerning LA-MC-ICP-MS argued by some scholars [10], the data obtained by this method has proven to be reliable [11-13]. The laser ablation system is New Wave UP Femto made by the ESI company. The national standard material of GBW02137 is taken as the external reference material for quality control. The results of the fifteen copper (brass, bronze) national standard materials show that GBW02137 can also be used as external reference material for in-situ microanalysis of $\mathrm{Pb}$ isotope in bronze, brass, and copper ore based on copper [12]. In addition, the internal precision $\mathrm{RSE}$ of ${ }^{208} \mathrm{~Pb} /{ }^{204} \mathrm{~Pb}$ and ${ }^{207} \mathrm{~Pb} /{ }^{206} \mathrm{~Pb}$ ratios is less than
90 and $40 \mathrm{ppm}$, and the external precision RSD is less than 60 and $30 \mathrm{ppm}$, respectively. We tested four to five points for each sample and took the average value. We also measured and calculated the standard deviation of the lead isotope ratios for the slags and bronzes. The specific experimental parameters of the whole set of equipment are shown in Additional file 1: Table S2.

\section{Results and discussions}

Based on the threshold of $2 \%$ alloying element content, ancient Chinese bronzes fall into three main categories: tin bronze, lead bronze, and lead-tin bronze. Generally, 


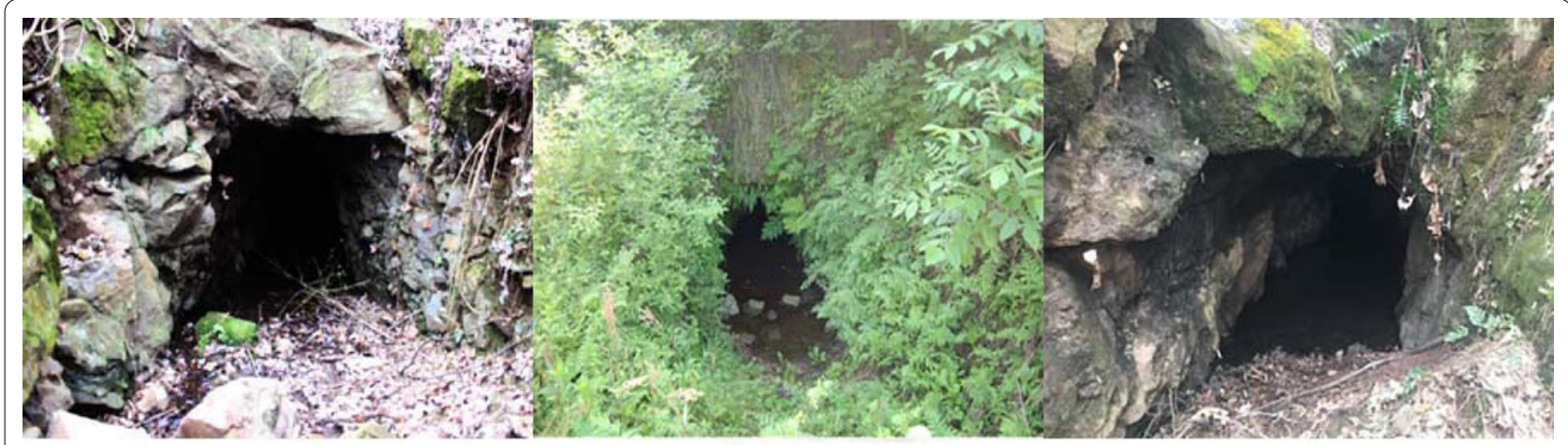

a. Drift of Shadun

b. Drift of Luohuangdou

c. Drift of Jiangjiawa

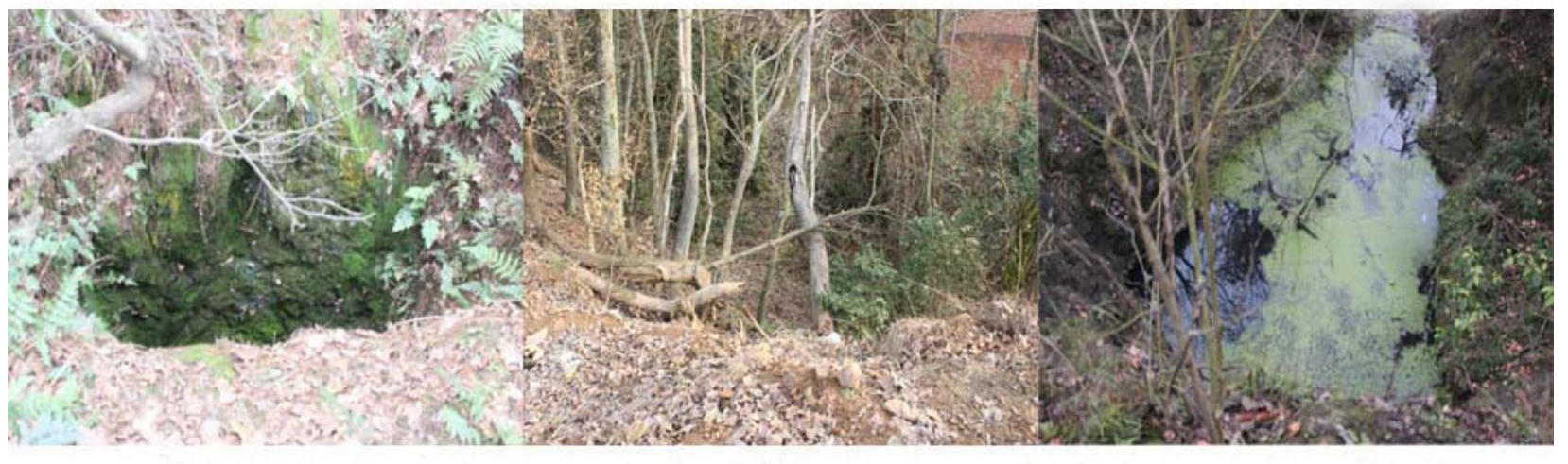

c. Vertical shaft of xiaoshuzui

d. Open mining pit of Tongkeng

e. Vertical shaft and trough of Tongkeng

Fig. 2 Mining remains discovered in the survey

the lead isotope ratios point to the source of lead material if the lead content in lead bronze and lead-tin bronze is higher than $2 \%$ [14], whereas the lead isotopes of pure copper and tin ware should be indicative of the source of copper ore and tin ore, respectively [15]. There are two points about the lead isotope information of tin bronze can be discussed in two cases: (1) The content of copper in tin bronze is about 5-20 times that of tin, so the results of the lead isotope of this kind of tin bronze should reflect the source of the copper ore. (2) If the copper material is relatively pure, then lead mainly comes from tin material, and the results should indicate the source information of tin material [16]. In terms of the slags produced during the smelting process of copper ores, the results of lead isotope ratios directly reflect the source information of copper ore [17].

\section{Lead isotope analysis Lead isotope ratios analysis of the slags from Tangjiadun}

The results of the lead isotope ratios analysis of the slags from the Tangjiadun site in Zongyang along with those from other sites in Nanling, Tongling are shown in Table 2 (the data of every point for the samples shown in
Additional file 1: Table S3). Table 2 reveals that the data are distributed between 2.085 and 2.136 on ${ }^{208} \mathrm{~Pb} /{ }^{206} \mathrm{~Pb}$, 0.844 and 0.871 on ${ }^{207} \mathrm{~Pb} /{ }^{206} \mathrm{~Pb}$. All the data fall into the range of common lead, with no anomalous lead being detected. Figure 5 shows that the lead isotope ratios of all the slags exhibit a linear distribution as a whole. The lead isotope ratios of the Tangjiadun slags are relatively concentrated with the smelting sites of the Western Zhou Dynasty in the Wannan region, such as Jinshansheng, Muyushan, Wanyingshan, and Jiangmuchong site, indicative of the same sources of the ore materials.

Until now, nearly 100 ancient copper mining and smelting sites have been found along the Yangtze River basin in Anhui Province, which are mainly distributed in the Wannan region (Tongling, Nanling, Fanchang, Qingyang, Guichi, and Jingxian, etc.), Zong-Lu (ZongyangLujiang) and Chu-Ma (Chuzhou-Ma'anshan) areas. The sites spread over thousands of square kilometers and range from the Shang and Zhou Dynasties to the Ming and Qing Dynasties. With the excavation of the Shigudun site in Tongling in 2010, the date of the smelting and casting activities in the Wannan region were brought forward to the third and fourth stages of the Erlitou Culture 


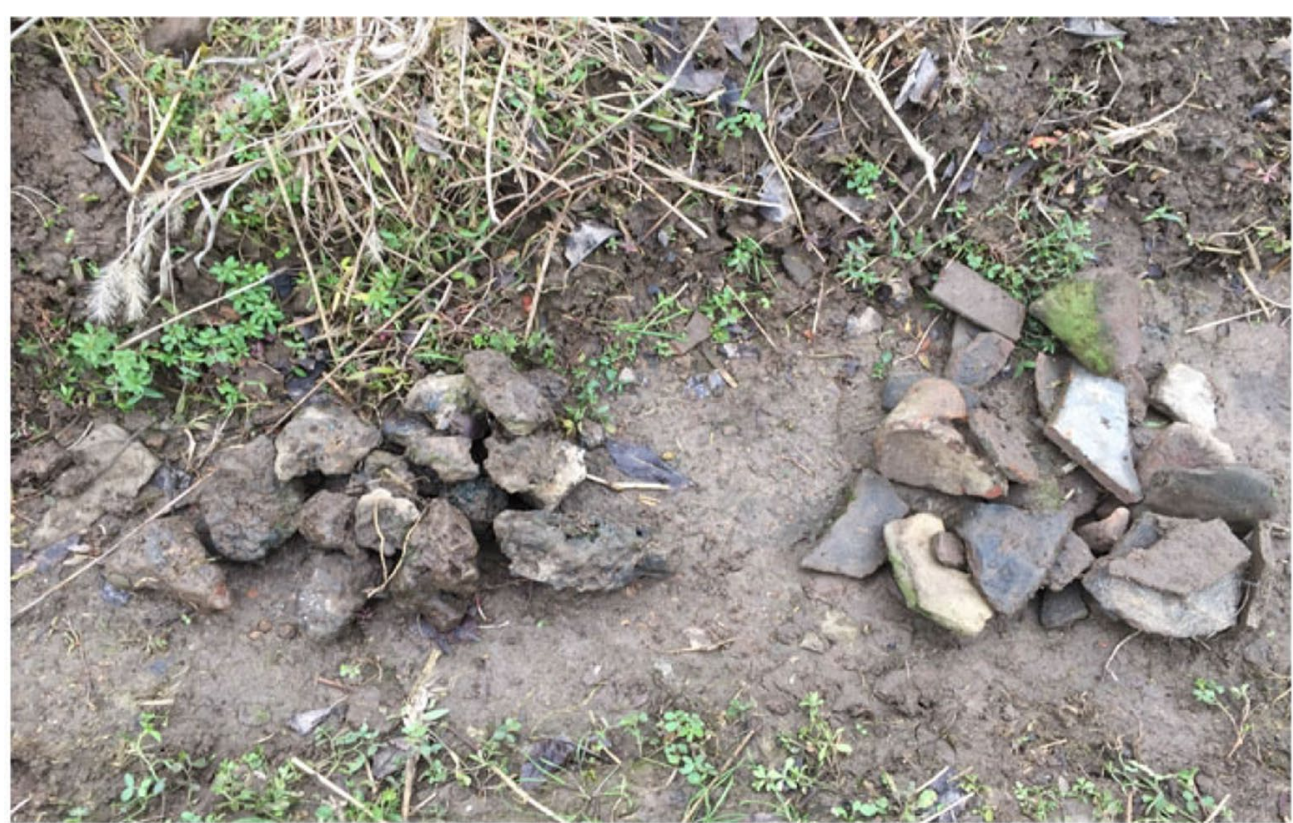

a. Slags and pottery shreds of Boat-shaped cattle-shaped site

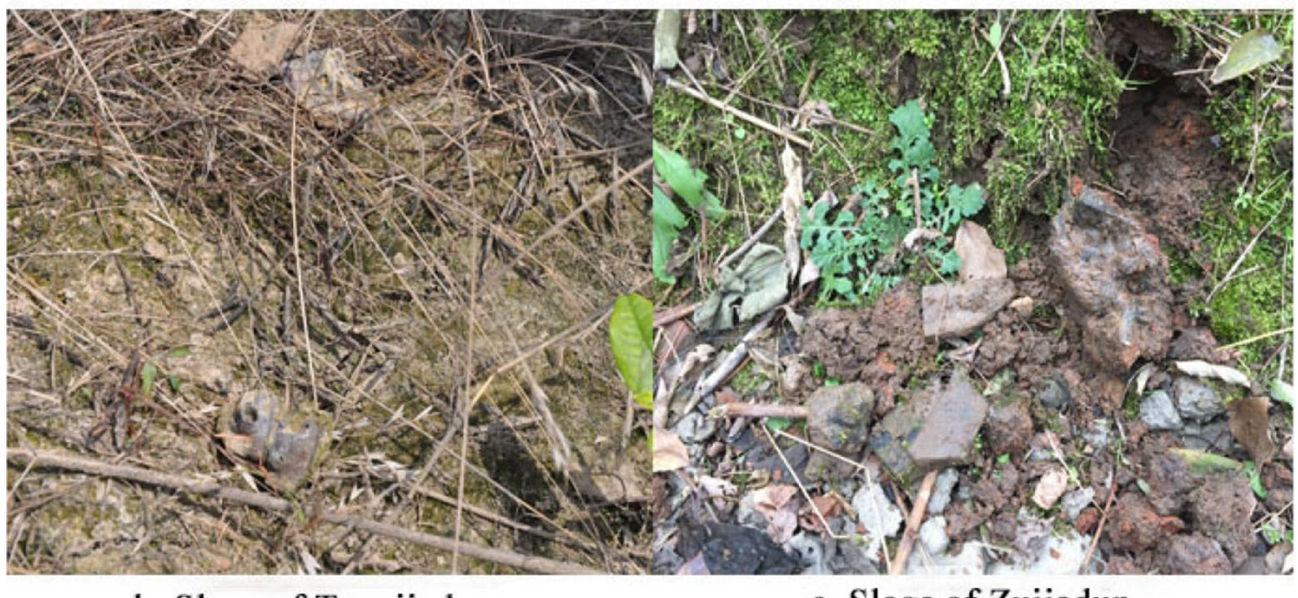

\section{b. Slags of Tangjiadun}

c. Slags of Zujiadun

Fig. 3 Slags and pottery shreds collected from the mining and smelting sites of Zongyang

(1750BC-1530BC [18]) [19, 20]. Yet the smelting and casting activities occurred in the Zongyang area until the late Shang Dynasty, as represented by the Tangjiadun site, later than those in the Wannan region. Geographically, the Tangjiadun site is located on the west bank of the Yangtze River and faces the Wannan region across the river, having convenient water transport conditions. Tangjiadun is also closer to the mining areas in the Wannan region than to the Zongyang mining area. Therefore, it is possible that the metal resources from the Wannan region could have been transferred westward to the Zongyang region during the late Shang Dynasty.

\section{Lead isotope ratios of the Zongyang bronzes}

The elemental composition of the Zongyang bronzes shows that they are all lead-tin bronzes (Table 3 and Additional file 1: Table S4). All the samples from Zongyang contain more than $2 \%$ lead. For data with lead content more than $2 \%$, the lead isotope data in this paper are applied to discuss the sources of lead rather than of copper. The distribution of tin in the Zongyang bronzes is $2.96-13.19 \%$. According to the research by Pollard et al. [21, 22], the approximately normal distribution of tin centered suggests that it should have been added to 
Table 1 Sample profile

\begin{tabular}{|c|c|c|c|c|c|}
\hline Sample ID & Collection number & Sample type & Period & Sampling information & Site \\
\hline$z y-1$ & T00110 & Bronze Yi & Spring and Autumn period & Pan debris & Yangshi village of Zongyang \\
\hline$z y-2$ & T00055 & Bronze spoon & Warring States & Abdominal debris & Qishan village of Zongyang \\
\hline$z y-3$ & T00053 & Ding with iron foot & Warring States & Cover debris & $\begin{array}{l}\text { Laozhuang village of Zong- } \\
\text { yang }\end{array}$ \\
\hline$z y-4$ & T00065 & Bronze Ding & Warring States & Abdominal debris & Qishan village of Zongyang \\
\hline$z y-5$ & T00065 & Bronze Ding & Warring States & Abdominal debris & Qishan village of Zongyang \\
\hline$z y-6$ & T00159 & $\begin{array}{l}\text { Hu with cord impressions } \\
\text { design }\end{array}$ & Warring States & Cover debris & Qishan village of Zongyang \\
\hline$z y-7$ & T00034 & Ding with iron foot & Warring States & Abdominal debris & Qishan village of Zongyang \\
\hline$z y-8$ & T00154 & Bronze Ge & Warring States & Debris & $\begin{array}{l}\text { Laozhuang village of Zong- } \\
\text { yang }\end{array}$ \\
\hline$z y-9$ & T00059 & Bronze Spear & Warring States & Qiong debris & $\begin{array}{l}\text { Chenjiawan village of } \\
\text { Zongyang }\end{array}$ \\
\hline$z y-10$ & T00139 & Ding with qiequ design & Western Zhou Dynasty & Mouth edge debris & $\begin{array}{l}\text { Qiancheng village of Guan- } \\
\text { qiao town in Zongyang }\end{array}$ \\
\hline$z y-11$ & T00140 & Ding with standing ears & Western Zhou Dynasty & Abdominally broken place & $\begin{array}{l}\text { Qiancheng village of Guan- } \\
\text { qiao town in Zongyang }\end{array}$ \\
\hline$z y-12$ & T00138 & Jue with bow string design & Western Zhou Dynasty & Abdominal fracture & $\begin{array}{l}\text { Qiancheng village, Guanqiao } \\
\text { Town, Zongyang }\end{array}$ \\
\hline$z y-13$ & T00141 & Bronze Zun & Western Zhou Dynasty & Circle foot fragmentation & $\begin{array}{l}\text { Qiancheng village of Guan- } \\
\text { qiao town in Zongyang }\end{array}$ \\
\hline LZ-1 & - & Slag & Western Zhou Dynasty & - & $\begin{array}{l}\text { Jinshansheng smelting site } \\
\text { in Tongling }\end{array}$ \\
\hline LZ-2 & - & Slag & Western Zhou Dynasty & - & $\begin{array}{l}\text { Muyushan smelting site in } \\
\text { Tongling }\end{array}$ \\
\hline LZ-3 & - & Slag & Western Zhou Dynasty & - & $\begin{array}{l}\text { Wangyingshan smelting site } \\
\text { in Tongling }\end{array}$ \\
\hline LZ-4 & - & Slag & Late Shang Dynasty & - & Tangjiadun in Zongyang \\
\hline LZ-5 & - & Slag & Late Shang Dynasty & - & Tangjiadun in Zongyang \\
\hline LZ-6 & - & Slag & Eastern Zhou Dynasty & - & $\begin{array}{l}\text { Yanzimu smelting site in } \\
\text { Tongling }\end{array}$ \\
\hline LZ-7 & - & Slag & Western Zhou Dynasty & - & $\begin{array}{l}\text { Jiangmuchong smelting site } \\
\text { in Nanling }\end{array}$ \\
\hline HY-1 & 02cht1206(5) & - & Shang and Zhou Dynasties & Debris of bronze ware & Heying site in Chuzhou \\
\hline $\mathrm{HY}-2$ & 02cht0707 & - & Shang and Zhou Dynasties & Debris of bronze ware & Heying site in Chuzhou \\
\hline $\mathrm{HY}-3$ & 02cht10078) & - & Shang and Zhou Dynasties & Debris of bronze ware & Heying site in Chuzhou \\
\hline $\mathrm{HY}-4$ & 02cht1105-1 & - & Shang and Zhou Dynasties & Debris of bronze ware & Heying site in Chuzhou \\
\hline HY-5 & 02cht11048) & - & Shang and Zhou Dynasties & Debris of bronze ware & Heying site in Chuzhou \\
\hline
\end{tabular}

zy-4 and zy-5 are different parts of the same sample

the primary alloy deliberately rather than inadvertently in the recycling and remelting process.

We can see from Fig. 6 and Table 4 that there are two categories of lead materials used for the Zongyang bronzes. Class I lead materials, with the lead isotope ratios of ${ }^{208} \mathrm{~Pb} /{ }^{206} \mathrm{~Pb}$ ranging from 2.09 to 2.12 and the ratios of ${ }^{207} \mathrm{~Pb} /{ }^{206} \mathrm{~Pb}$ ranging from 0.84 to 0.86 , were mainly used for the bronzes between the Western Zhou Dynasty and the Spring and Autumn period. Class II lead materials were mainly used for the bronzes in the Warring States period, and the lead isotope ratios range from 2.12 to 2.16 for ${ }^{208} \mathrm{~Pb} /{ }^{206} \mathrm{~Pb}$ and from 0.86 to 0.88 for ${ }^{207} \mathrm{~Pb} /{ }^{206} \mathrm{~Pb}$. The ratios of one single bronze in the Western Zhou Dynasty fall into the concentration area of Class II, indicating that Class II lead materials could have been used in a small amount during the Western Zhou Dynasty and, accordingly, this usage would have continued during the Warring States period.

To know the differences between the lead materials used for the bronzes from Zongyang and those from the surrounding area, the lead isotope ratios of the bronzes unearthed from Shou County [23], Lu'an [23], and Heying (Table 4) in the Jianghuai region are selected for a comparative study. It can be seen from Fig. 7 that the 


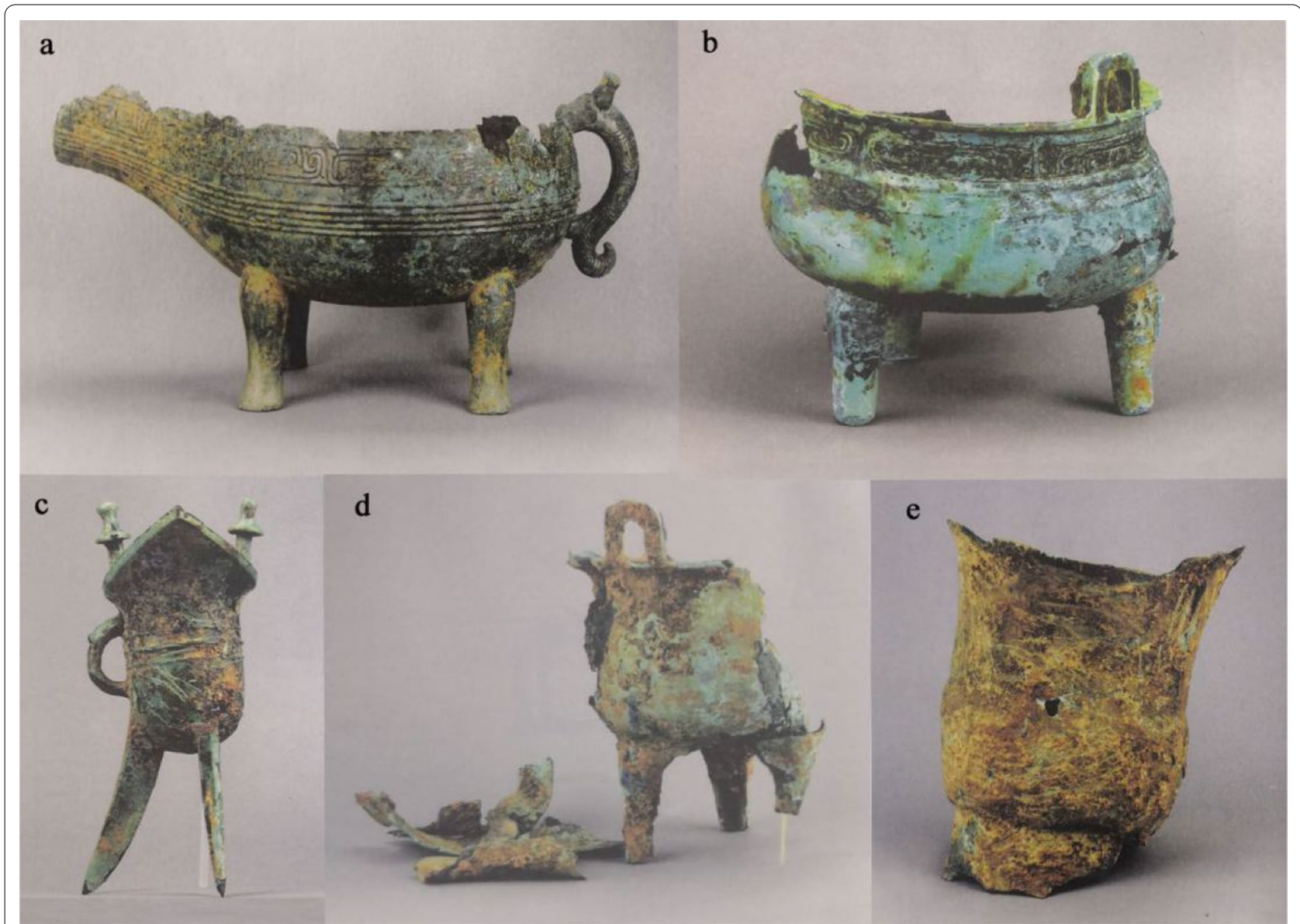

Fig. 4 The bronze vessels unearthed from Zongyang (a zy-1; b zy-10; c zy-12; d zy-11; e zy-13)

Table 2 Results of the lead isotope ratios of the slags from the Wannan region

\begin{tabular}{|c|c|c|c|c|c|c|c|c|c|c|}
\hline Sample ID & $208 \mathrm{~Pb} / 206 \mathrm{~Pb}$ & SD & $207 \mathrm{~Pb} / 206 \mathrm{~Pb}$ & SD & $206 \mathrm{~Pb} / 204 \mathrm{~Pb}$ & SD & $207 \mathrm{~Pb} / 204 \mathrm{~Pb}$ & SD & $208 \mathrm{~Pb} / 204 \mathrm{~Pb}$ & SD \\
\hline LZ-1 & 2.100 & 0.00044 & 0.851 & 0.00024 & 18.385 & 0.01169 & 15.635 & 0.01083 & 38.613 & 0.02520 \\
\hline LZ-2 & 2.098 & 0.00331 & 0.851 & 0.00004 & 18.357 & 0.00234 & 15.615 & 0.00239 & 38.513 & 0.05846 \\
\hline LZ-3 & 2.113 & 0.00234 & 0.859 & 0.00124 & 18.175 & 0.04282 & 15.611 & 0.01670 & 38.386 & 0.05172 \\
\hline LZ-4 & 2.092 & 0.00330 & 0.848 & 0.00175 & 18.414 & 0.04238 & 15.622 & 0.01386 & 38.514 & 0.04775 \\
\hline LZ-5 & 2.095 & 0.00312 & 0.849 & 0.00173 & 18.417 & 0.04597 & 15.641 & 0.01713 & 38.569 & 0.06255 \\
\hline LZ-6 & 2.136 & 0.00136 & 0.871 & 0.00073 & 17.867 & 0.01932 & 15.565 & 0.00631 & 38.153 & 0.02072 \\
\hline LZ-7 & 2.085 & 0.00094 & 0.844 & 0.00049 & 18.541 & 0.02805 & 15.644 & 0.01811 & 38.661 & 0.05329 \\
\hline
\end{tabular}

bronzes of Shou County, Lu'an, and Heying also utilized two kinds of lead materials: Class I for the bronzes from the Western Zhou Dynasty to the Spring and Autumn period and Class II for those in the Warring States period, consistent with the lead materials of the Zongyang bronzes. The shift in the lead materials has aroused interest among some domestic scholars [24]. According to historical records, wars between the Zhou court and the Huaiyi tribes in the Jianghuai region had been frequent from the middle Western Zhou period onward. During the Spring and Autumn period and the Warring States period, the Jianghuai region became a battleground for the states fighting for supremacy. Hence, we propose that the change of the lead isotope ratios of bronzes might have been a by-product of the dynamic of the political arena at that time. 


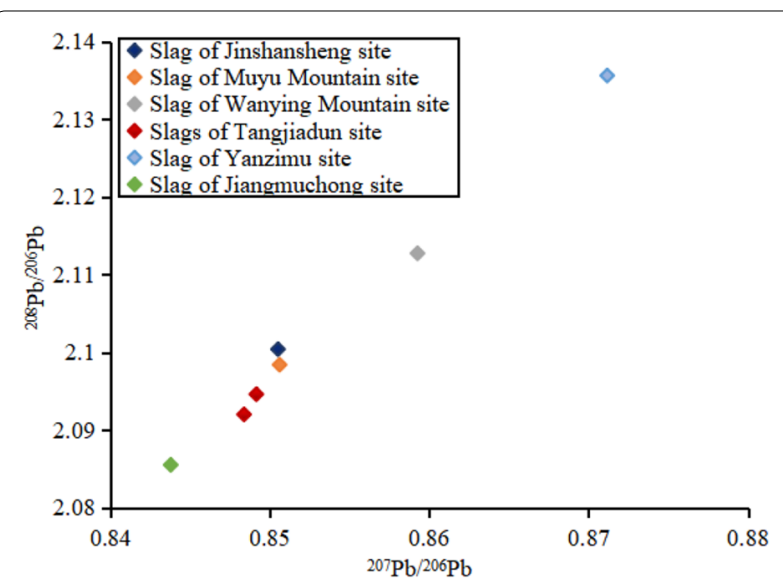

Fig. 5 The plots of the lead isotope ratios of the slags from the Wannan region and Tangjiadun site

Table 3 Result of the EDXRF analysis of the bronze vessels of Zongyang (\%)

\begin{tabular}{|c|c|c|c|c|}
\hline Sample ID & $\mathrm{Cu}$ & Sn & $\mathrm{Pb}$ & Alloy type \\
\hline$z y-1$ & 71.05 & 17.80 & 5.71 & $\mathrm{~Pb}-\mathrm{Sn}$ bronze \\
\hline$z y-6$ & 72.13 & 19.94 & 2.96 & $\mathrm{~Pb}-\mathrm{Sn}$ bronze \\
\hline$z y-5$ & 71.33 & 11.10 & 11.51 & $\mathrm{~Pb}-\mathrm{Sn}$ bronze \\
\hline$z y-10$ & 71.07 & 18.28 & 4.53 & $\mathrm{~Pb}-\mathrm{Sn}$ bronze \\
\hline$z y-2$ & 68.48 & 10.54 & 13.19 & $\mathrm{~Pb}-\mathrm{Sn}$ bronze \\
\hline$z y-3$ & 80.55 & 9.87 & 3.19 & $\mathrm{~Pb}-\mathrm{Sn}$ bronze \\
\hline$z y-7$ & 73.08 & 9.68 & 11.56 & $\mathrm{~Pb}-\mathrm{Sn}$ bronze \\
\hline$z y-13$ & 80.25 & 4.58 & 10.49 & $\mathrm{~Pb}-\mathrm{Sn}$ bronze \\
\hline$z y-11$ & 79.60 & 5.29 & 9.70 & $\mathrm{~Pb}-\mathrm{Sn}$ bronze \\
\hline$z y-12$ & 78.48 & 12.62 & 3.43 & $\mathrm{~Pb}-\mathrm{Sn}$ bronze \\
\hline
\end{tabular}

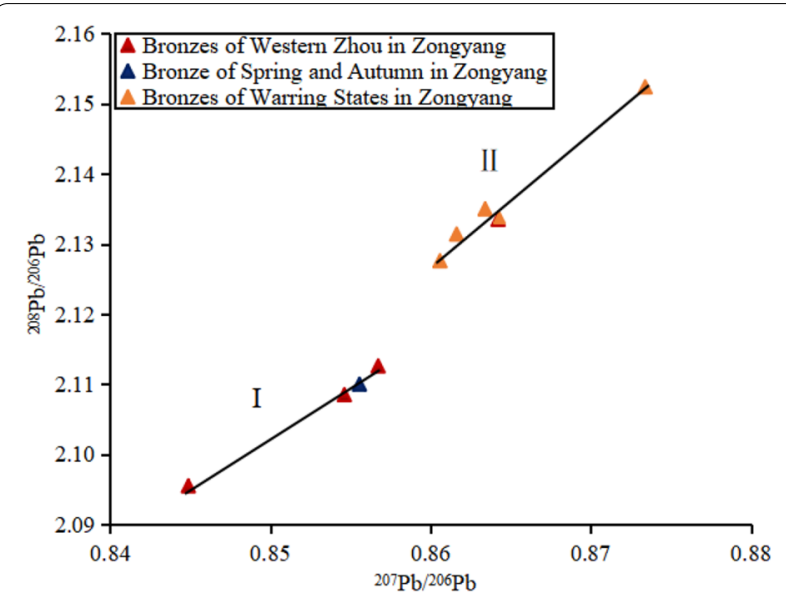

Fig. 6 The plot of the lead isotope ratios of the bronze vessels unearthed from Zongyang
For exploring the sources of Class I and II lead materials, we selected the lead isotope ratios of the mining areas in Zongyang, Wannan, and Hubei for comparative studies. We can see from Fig. 8 that although the lead isotope ratios of the Zongyang bronzes all fall into the ratio range of the mining areas along the Yangtze River in Anhui Province, both Class I and Class II lead materials could come from different mines. The lead isotope ratios of Class I all fall into the range of the Wannan mining area, but far from the data of the lead ores in Zongyang, which indicates that Class I lead materials were probably from Wannan, rather than the Zongyang mining area. The isotope ratios of Class II lead materials roughly coincide with those from the Zongyang and the Hubei mining areas.

Based on a scientific analysis of pottery samples and clay cores of the pre-Qin period from the Tongling and the Feidong areas, it has been proved that the bronzes unearthed in Anhui were not all cast in the Central Plain [25]. Given that the bronzes unearthed in Zongyang bear the local characteristics [9] and that people in Zongyang involved in smelting and casting activities during the late Shang Dynasty, the bronze vessels of Zongyang likely were cast locally. With the exploitation of the local metal resources during the Eastern Zhou Dynasty, it was more convenient to use the local mineral resources than those in Hubei. In addition, jin-dao xi-hang (金道锡行), a term recorded in the Official Histories meaning the routes along which copper, tin and other bronze raw materials were transported to the Central Plain, has been proven by scholars to have existed as far back as the Shang and Zhou Dynasties [26-28], and that there were different routes in Jianghan and Jianghuai regions. Obviously, with the local resources at hand, it is unlikely that people sought long-distance mineral materials from Hubei. We believe that during the Warring States period the Class II lead materials must have come from the local mines in Zongyang.

\section{Trace element analysis}

Trace elements in copper alloys can provide useful information for the sources of metals [29]. The trace elements $\mathrm{Co}, \mathrm{Ni}, \mathrm{As}, \mathrm{Au}, \mathrm{Ag}, \mathrm{Se}, \mathrm{Te}$, and $\mathrm{Bi}$ are indicative of the provenance of the raw materials for the bronze vessels [30, 31]. The above indicative elements in the Zongyang bronzes were measured with LA-ICP-MS by Qin et al. in 2017 [3], the results shown in Additional file 1: Table S5. To further explore the ore material sources of the Zongyang bronzes, we re-analyzed the trace element data with the Oxford Research System.

We used the Oxford Research System, carried out by the archaeometallurgical team at Oxford University, as a main data process method to summarize the chemical 
Table 4 Result of lead isotope analysis of bronze artifacts unearthed from the site in Zongyang and Chuzhou

\begin{tabular}{|c|c|c|c|c|c|c|c|c|c|c|}
\hline Sample ID & $208 \mathrm{~Pb} / 206 \mathrm{~Pb}$ & SD & $207 \mathrm{~Pb} / 206 \mathrm{~Pb}$ & SD & $206 \mathrm{~Pb} / 204 \mathrm{~Pb}$ & SD & $207 \mathrm{~Pb} / 204 \mathrm{~Pb}$ & SD & $208 \mathrm{~Pb} / 204 \mathrm{~Pb}$ & SD \\
\hline$z y-1$ & 2.110 & 0.00054 & 0.856 & 0.00008 & 18.258 & 0.01590 & 15.620 & 0.01394 & 38.522 & 0.04715 \\
\hline$z y-6$ & 2.134 & 0.00036 & 0.864 & 0.00006 & 18.091 & 0.00504 & 15.636 & 0.00562 & 38.599 & 0.01836 \\
\hline$z y-5$ & 2.152 & 0.00051 & 0.873 & 0.00013 & 17.838 & 0.01242 & 15.580 & 0.01355 & 38.392 & 0.03551 \\
\hline$z y-10$ & 2.134 & 0.00029 & 0.864 & 0.00004 & 18.086 & 0.00558 & 15.632 & 0.00570 & 38.586 & 0.01522 \\
\hline$z y-3$ & 2.131 & 0.00037 & 0.862 & 0.00009 & 18.145 & 0.00577 & 15.635 & 0.00606 & 38.675 & 0.01652 \\
\hline$z y-2$ & 2.128 & 0.00035 & 0.861 & 0.00006 & 18.197 & 0.01073 & 15.660 & 0.01130 & 38.714 & 0.03100 \\
\hline$z y-7$ & 2.135 & 0.00059 & 0.863 & 0.00017 & 18.094 & 0.01241 & 15.622 & 0.00925 & 38.631 & 0.02846 \\
\hline$z y-13$ & 2.113 & 0.00018 & 0.857 & 0.00006 & 18.239 & 0.01030 & 15.626 & 0.01127 & 38.534 & 0.02922 \\
\hline$z y-11$ & 2.109 & 0.00065 & 0.855 & 0.00016 & 18.290 & 0.01901 & 15.630 & 0.01706 & 38.557 & 0.04773 \\
\hline$z y-12$ & 2.096 & 0.00050 & 0.845 & 0.00016 & 18.628 & 0.01411 & 15.737 & 0.01245 & 39.028 & 0.03144 \\
\hline $\mathrm{HY}-1$ & 2.166 & 0.00057 & 0.887 & 0.00008 & 17.547 & 0.01597 & 15.569 & 0.01580 & 37.999 & 0.03721 \\
\hline $\mathrm{HY}-2$ & 2.100 & 0.00028 & 0.852 & 0.00006 & 18.324 & 0.00733 & 15.605 & 0.00723 & 38.479 & 0.01961 \\
\hline$H Y-3$ & 2.128 & 0.00059 & 0.866 & 0.00005 & 17.973 & 0.00340 & 15.570 & 0.00417 & 38.243 & 0.01831 \\
\hline$H Y-4$ & 2.094 & 0.00057 & 0.848 & 0.00021 & 18.421 & 0.05644 & 15.621 & 0.04033 & 38.554 & 0.12473 \\
\hline HY-5 & 2.087 & 0.00026 & 0.846 & 0.00010 & 18.426 & 0.00780 & 15.595 & 0.00730 & 38.483 & 0.01920 \\
\hline
\end{tabular}

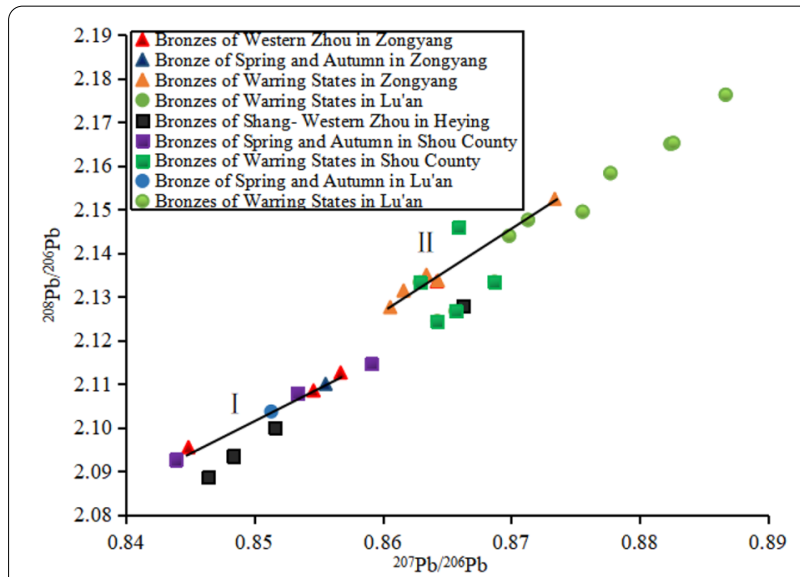

Fig. 7 The plot of the lead isotope ratios of the bronze vessels from Zongyang, Lu'an, Heying and Shou County

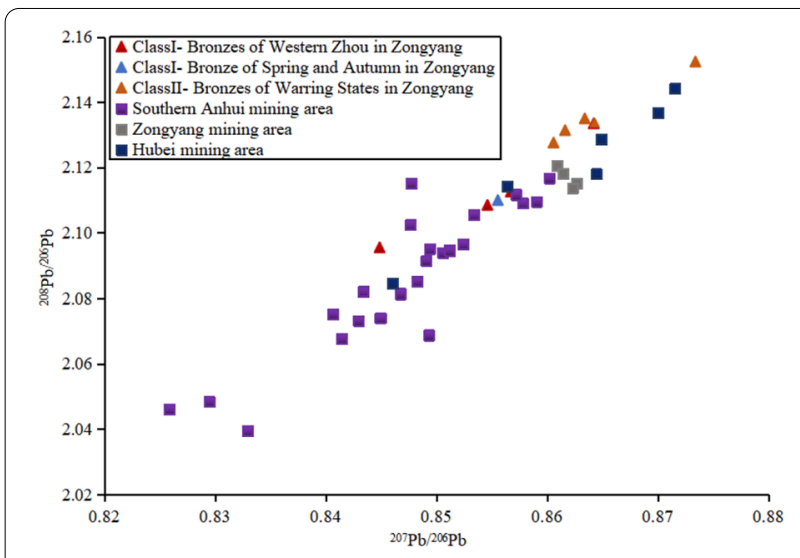

Fig. 8 The plot of the lead isotope ratios of the bronzes from Zongyang and various mining areas composition of the Zongyang bronzes. Elsewhere, this research system has been discussed in detail and made some achievements in a research of certain Chinese bronzes [21, 22, 32-41]. In this study, we applied the 'Copper Groups' method. Based on the presence/absence $(\mathrm{Y} / \mathrm{N})$ of the four most commonly reported trace elements-arsenic (As), antimony ( $\mathrm{Sb})$, silver (Ag), and nickel $(\mathrm{Ni})$, the method could allocate the metal composition to one of 16 categories. For most datasets, $0.1 \%$ (after mathematical removal of any major alloying elements present and renormalization) is used as a cut-off for the division between presence and absence [32].

Table 5 reveals the results of the groups analysis. There are two groups present in the Western Zhou and the following Spring and Autumn period: CG9 (As-Ag) and CG12 (As-Sb-Ag). During the Warring States period, CG9 disappeared, whereas CG16 (As-Ag-Sb-Ni) and CG1 (clean metal) appeared, suggesting that the sources of the ore materials for the Zongyang bronzes changed during this period. However, CG12 continued from the Western Zhou Dynasty to the Warring States period, which had been used consistently throughout the Zhou Dynasty.

It is worthwhile to pay special attention to the element silver. It can be seen from Table 5 that almost all the samples contain silver and the silver content is $0.12-0.81 \%$. Scholars have long hypothesized that silver can offer an independent proxy to characterize lead minerals. It has also been proven that the silver concentration can help to identify the number of the lead sources of the Shang Dynasty bronzes [37]. In the past, much of the world's silver was obtained from silver-containing minerals, especially galena $(\mathrm{PbS})$, with 
Table 5 Statistics on the grouping of the bronze vessels from Zongyang (Y: yes; N: no)

\begin{tabular}{|c|c|c|c|c|c|c|}
\hline \multirow[t]{2}{*}{ Sample ID } & \multirow[t]{2}{*}{ Period } & \multicolumn{4}{|c|}{ Element presence or absence } & \multirow[t]{2}{*}{ Copper group } \\
\hline & & As & $\mathrm{Sb}$ & $\mathrm{Ag}$ & $\mathrm{Ni}$ & \\
\hline$z y-10$ & \multirow[t]{4}{*}{ Western Zhou Dynasty } & Y & $N$ & Y & N & CG9 \\
\hline$z y-11$ & & Y & $\mathrm{N}$ & Y & $\mathrm{N}$ & CG9 \\
\hline$z y-12$ & & Y & Y & Y & $\mathrm{N}$ & CG12 \\
\hline$z y-13$ & & Y & N & Y & $\mathrm{N}$ & CG 9 \\
\hline$z y-1$ & Spring and Autumn period & Y & N & Y & N & CG9 \\
\hline$z y-3$ & \multirow[t]{6}{*}{ Warring States } & Y & Y & Y & $\mathrm{N}$ & CG12 \\
\hline$z y-4$ & & Y & Y & Y & Y & CG16 \\
\hline$z y-5$ & & Y & Y & Y & Y & CG16 \\
\hline$z y-6$ & & Y & Y & Y & Y & CG16 \\
\hline$z y-7$ & & Y & Y & Y & $\mathrm{N}$ & CG12 \\
\hline$z y-8$ & & $\mathrm{~N}$ & $\mathrm{~N}$ & $\mathrm{~N}$ & $\mathrm{~N}$ & CG1 \\
\hline
\end{tabular}

a small amount coming from copper ores. Galena was smelted to produce lead which might contain up to $1 \%$ silver, while raw copper typically contained $<0.3 \%$ silver [37]. According to correlation analysis, the correlations between $\mathrm{Ag}$ and $\mathrm{Cu}$ show a weak but negative correlation $\left(R^{2}=0.1259\right)$, while those between $\mathrm{Ag}$ and $\mathrm{Pb}$ show a relatively strong positive correlation $\left(R^{2}=0.2339\right)$. Although one might argue that the value of $R^{2}$ is relatively low, it is still significant that the silver in the Zongyang bronzes may have resulted from the addition of lead, with no connection to the base copper.

Overall, the results of the trace elements of the Zongyang bronzes are consistent with those of the lead isotope analysis. All the results imply that the provenance of the Zongyang bronzes was stable between the Western Zhou Dynasty and the Spring and Autumn period, whereas the changes of ore source happened during the Warring States period. In the Western Zhou Dynasty and the Spring and Autumn period, during a relatively stable political landscape under the rule of the Qunshu state, the Zongyang area was strongly influenced by the Dongyi and the Qunshu cultures [9]. After 615 BC around the middle Spring and Autumn period, as the Qunshu state was annexed by the Chu state [42], Zongyang became a part of the Chu state, where the dominant $\mathrm{Chu}$ culture coexisted with other cultures such as the Central Plain, Wu, and Yue [9]. To compete for power and hegemony, the states of Chu and Wu fought a 60-year war in the south of the Yangtze River and the Wu-Yue wars lasted roughly for two decades. The continuous wars inevitably had an impact on the output of copper materials in Wannan and to a large degree shaped the changes of the ore sources of the Zongyang bronzes during the Warring States period.

\section{Conclusions}

The lead isotope analysis on the bronze vessels showed that two kinds of lead materials were used for the bronzes of Zongyang. Class I lead materials were mainly used in the Western Zhou and the Spring and Autumn period, and could have originated from the mining area in the Wannan region. Connecting this finding with the lead isotope analysis results of the Tangjiadun slags, we propose that the ore materials in the Wannan region could been transported to the Zongyang area across the Yangtze River in the late Shang Dynasty and continued to be used until the Warring States period. Class II lead materials were mainly used in the Warring States period, which perhaps came from the local mines of Zongyang. The results of the trace elements also reveal the changes in ore material source used for the Zongyang bronzes during the Warring States period, which are consistent with the conclusions of the lead isotope analysis. It can be seen that changes to the material sources happened during the Warring State period in Zongyang and the political turmoil contributed to the changes.

Basing on the field surveys and excavations of the mining and smelting sites in Zongyang, we infer that the complete bronze industrial system including copper mining, smelting, and bronze casting had developed in the Zongyang area no later than the Eastern Zhou Dynasty. Wars between the Zhou state and the Huaiyi tribes are documented in classics such as the "ZuoZhuan" (左传, The Commentary of Zuo) and Shijing (诗经, The Books of Songs) and in unearthed bronze inscriptions. Some scholars argued that the wars were triggered by the Zhou state's desire to control the copper resources in the lower reaches of the Yangtze River [43-46]. Considering the fact that received historical records attest to the 
transportation routes of copper, tin and other bronze raw materials (金道锡行), and that these the routes existed as far back as the Shang and Zhou dynasties, our team concludes from the excavated data analyzed above that the Zongyang area could have been one of the essential channels by which the copper resources were imported into the Central Plains.

\section{Supplementary Information}

The online version contains supplementary material available at https://doi. org/10.1186/s40494-021-00566-5.

Additional file 1: Table S1. Potteries unearthed from major sites of Zong yang in Shang and Zhou Dynasties. Table S2. Instrument parameters of LA-MC-ICP-MS. Table S3. Lead isotope ratios for the bronze vessels and the slags from various sites. Table S4. Result of EDXRF analysis on the Zongyang bronzes (\%). Table S5. Result of trace elements analysis of bronze vessels from Zongyang $\left(\mu \mathrm{g} \mathrm{g}^{-1}\right)$.

\section{Acknowledgements}

The authors wish to thank Dr. Jianping Yue (Anhui University) for his valuable assistance on this study. We also are grateful to the anonymous reviewers whose comments greatly improved the quality of the manuscript.

\section{Authors' contributions}

YW and GW performed the data analysis and were major contributors in writing the manuscript. QL edited and modified the English sentence format, $\mathrm{XZ}$ analyzed the lead isotope data, and DW assisted in obtaining samples. All authors read and approved the final manuscript.

\section{Funding}

This research is supported by the National Social Science Fund of China (17ZDA222).

\section{Availability of data and materials}

All data generated or analyzed during this study are included in this published article.

\section{Declarations}

\section{Competing interests}

The authors declare that they have no conflict of interest.

\section{Author details}

${ }^{1}$ School of History, Anhui University, Hefei 230039, China. ${ }^{2}$ Wenzhou Municipal Institute of Cultural Relics and Archaeology, Wenzhou 325000, China. ${ }^{3}$ Anhui Museum, Hefei 230031, China.

Received: 26 January 2021 Accepted: 21 July 2021

Published online: 20 August 2021

\section{References}

1. Wei GF, Gao SL, Qin Y, Wang LQ. Study on smelting remains of Tangjiadun site. Spectrosc Spectr Anal. 2017;3:929-32 (in Chinese).

2. Yu YB, Mei JJ, Zhang AB, Wang LQ. A preliminary scientific analysis of pre-Qin bronzes unearthed from Zongyang, Anhui Province. Cult Relics Central China. 2014;3:108-15 (in Chinese).

3. Wei GF, Qin Y, Wang LQ. Study on copper ores source of bronze vessels in Zongyang County, Anhui Province, dated from the Western Zhou Dynasty to Warring State period. Spectrosc Spectr Anal. 2017;11:3610-5 (in Chinese)
4. Zongyang Committee for the Compilation of Local Chronicles. Zongyang County records. Hefei: Huangshan Publishing House; 1998. p. 63 (in Chinese).

5. Yang LX. Ancient copper deposits along the Yangtze River in Anhui Province. Study Cult Relics. 1991;8:194-203 (in Chinese).

6. Wang $\mathrm{JH}$. A summary of archaeological investigation of ancient copper deposits in Anhui Province. Study Cult Relics. 1991;8:204-10 (in Chinese).

7. Anhui Provincial Institute of Cultural Relics and Archaeology, Cultural Relics Management Institute of Zongyang County. The copper mine investigation of Jingbian of Zongyang County in the Eastern Zhou. Southeast Cult. 1992:5:89-90 (in Chinese).

8. Anhui Institute of Cultural Relics and Archaeology. Excavation of Tangjiadun site in Zongyang County of Anhui. Cult Relics Central China. 2004;4:4-14 (in Chinese).

9. Zhang AB. Bronze Wares of Shang and Zhou Dynasties in Zongyang. Hefei: Anhui University Press; 2018. (in Chinese).

10. Pernicka E. Lead isotope ratios and the provenance of medieval silver. Archaeol Anthropol Sci. 2020;12:165.

11. Yuan HL, Chen KY, Bao ZA, Zong CL, Dai MN, Fan C, Yin C. Determination of lead isotope compositions of geological samples using femtosecond laser ablation MC-ICPMS. Geochemistry. 2013;58(32):3914-21.

12. Chen KY, Yuan HL, Bao ZA, Zong CL, Dai MN. Precise and accurate in situ determination of lead isotope ratios in NIST, USGS, MPI-DING and CGSG glass reference materials using femtosecond laser ablation MC-ICP-MS. Geostand Geoanal Res. 2014;38(1):5-21.

13. Bao ZA, Yuan WT, Yuan HL, Liu X, Chen KY, Zong CL. Non-matrix-matched determination of lead isotope ratios in ancient bronze artifacts by femtosecond laser ablation multi-collector inductively coupled plasma mass spectrometry. Int J Mass Spectrom. 2016;40(2):12-9.

14. Tian JH, Jin ZY, Li RL, Yan LF, Cui JY. An elemental and lead-isotopic study on bronze Helmets from royal tomb No. 1004 in Yin Ruins. Jianghan Archaeology. 2012;1:92-99 (in Chinese).

15. Jin ZY. Progress of lead isotope tracing in archaeological research. Acta Geosci Sin. 2003;6:548-51 (in Chinese).

16. Yu YB, Cui JL, Mei JJ, Chen KL, Chang HY, Huang FC. Some problems on the study of lead isotopic ratio of Yejiashan. Relics South. 2016;1:94-102 (in Chinese)

17. Cui JF, Tong WH, Wu XH. Lead isotope ratio analysis of copper slag and copper wares unearthed in Yuanqu City. Cult Relics. 2012;7:80-4 (in Chinese).

18. Zhang XL, Chou SH, Cai LZ, et al. The establishment and supplement of the archaeological chronology for Xinzhai-Erlitou-Erligang culture. Archaeology. 2007:8:74-89 (in Chinese).

19. Anhui Provincial Institute of Cultural Relics and Archaeology. Excavation of the Shigudun site in Tongling County, Anhui Province. Archaeology. 2013:6:3-23 (in Chinese).

20. Wang K, Cui JL, Shuo Z. Related problems of bronze smelting relics unearthed from Shigudun site in Tongling County, Anhui Province. Archaeology. 2013;7:91-104 (in Chinese)

21. Pollard AM, Bray PJ, Hommel P, Xu YG, Liu R, et al. The application of the Oxford research system in the study of ancient Chinese bronzes. Archaeology. 2017;1:95-106 (in Chinese).

22. Pollard AM, Bray PJ. A new method for combining lead isotope and lead abundance data to characterize archaeological copper alloys. Archaeometry. 2015;57(6):996-1008.

23. Wen J, Ling X, Zhao CC, et al. Primary analysis on lead isotope characteristics in Chu state bronzes in East-Zhou period unearthed from Liu'an District, Anhui Province. J Northwest Univ (Nat Sci Ed). 2013;6:1016-20 (in Chinese).

24. Zhang J, Cui JL. A preliminary study on lead isotope ratios of Eastern Zhou bronzes. Cult Relics Southern China. 2017;2:94-102 (in Chinese).

25. Huang $\mathrm{H}$. A study on casting places of bronze vessels excavated from Anhui and Hubei in recent years. Hefei: A dissertation for doctor's degree of University of Science and Technology of China; 2014. p. 81 (in Chinese).

26. Yi DS. A study on southern "Jindaoxihang" in Zhou Dynasty-concurrently discuss the formation of bronze raw materials trading center "Fantang." Soc Sci. 2018;1:146-56.

27. Xu F. On the management strategy of the Western Zhou Dynasty to the Jianghuai area of Anhui Province. Nanjing Mus. 2010;11:36-40 (in Chinese). 
28. Liu L, Chen XC. The formation of Chinese early state: on the relationship between the center and the periphery of Erlitou and Erligang periods. J Ancient Civilizations. 2002;1:71-133 (in Chinese).

29. Qin Y, Zhang JP, Wang CS, Dong YW. A study on the experiment of searching source of bronze material with trace elements. Southeast Cult. 2004:4:89-92 (in Chinese).

30. Wei GF, Qin Y, Yang LX, et al. A preliminary study on the output direction discrimination and marks of some ancient copper ores and their smelting products. Archaeology. 2009;1:85 (in Chinese)

31. Wei GF, Qin Y, Wang CS, et al. Provenance of the material for bronze vessels of the Shang and Zhou Dynasties unearthed from some areas of China. Acta Geol Sin. 2017;85(3):445 (in Chinese).

32. Bray PJ, Cuénod A, Gosden C, Hommel P, Liu R, Pollard AM. Form and flow: the 'karmic cycle' of copper. J Archaeol Sci. 2015;56:202-9.

33. Bray PJ, Pollard AM. A new interpretative approach to the chemistry of copper-alloy objects: source, recycling and technology. Antiquity. 2012;86(333):853-67.

34. Pollard AM, Bray PJ, Hommel P, Hsu Y, Liu R, Rawson J. Bronze Age metal circulation in China. Antiquity. 2017;91(357):674-87.

35. Pollard AM, Liu R, Rawson J, Tang X. From alloy composition to alloying practice: Chinese bronzes. Archaeometry. 2019;61(1):70-82.

36. Liu RL, Pollard AM, Rawson J, Tang X, Bray PJ, Zhang C. Panglongcheng, Zhengzhou and the movement of Metailin Early Bronze Age China. J World Prehist. 2019;32:393-428.

37. Liu RL, Pollard AM, Liu C, Rawson J. Every cloud has a silver lining: using silver concentration to identify the number of sources of lead used in Shang Dynasty Bronzes. Acta Geol Sin (Engl Ed). 2020;94(3):585-93.

38. Liu RL, Pollard AM, Cao Q, Liu C, Sainsbury V, Howarth P, Bray PJ, Huan LM, Yao BH, Fu YT, Tang JG. Social hierarchy and the choice of metal recycling at Anyang, the last capital of Bronze Age Shang China. Sci Rep. 2020;10:18794.

39. Li HC, Cui JF, Chen JL, Xu TJ. Verification and application of 'copper groups' method. Jianghan Archaeol. 2020;2:103-9 (in Chinese)

40. Hsu YK, Bray PJ, Hommel P, Pollard AM, Rawson J. Tracing the flows of copper and copper alloys in the Early Iron Age societies of the eastern Eurasian steppe. Antiquity. 2016;90(350):357-75.

41. Li HC, Zuo ZQ, Cui JF, Tian JB, Yang YD, Yi L, Zhou ZQ, Fan JN. Copper alloy production in the Warring States period (475-221 BCE) of the Shu state: a metallurgical study on copper alloy objects of the Baishoulu cemetery in Chengdu, China. Herit Sci. 2020;8:67.

42. (Spring and Autumn period) Zuo QM wrote, Jiang JC punctuated. Zuo Zhuan. Changsha: Yuelu Press; 1988. p. 106 (in Chinese).

43. Li XQ, Xu JJ. Cultural history of the Yangtze River. Nanchang: Jiangxi Education Publishing House; 1995. p. 151-63 (in Chinese).

44. Zeng $Z Y$, Yin HZ. Two problems in the history of ancient Jiangsu. Jianghai Acad J. 1961;12:1-30 (in Chinese).

45. Li XS. Discussion of Huaiyi. Southeast. Culture. 1991;5:14-21 (in Chinese)

46. Tang $L$. The question about Kang Palace in the dating of bronzes in the Western Zhou Dynasty. Acta Archaeologica Sinica. 1962;1:15-48 (in Chinese).

\section{Publisher's Note}

Springer Nature remains neutral with regard to jurisdictional claims in published maps and institutional affiliations.

\section{Submit your manuscript to a SpringerOpen ${ }^{\circ}$ journal and benefit from:}

- Convenient online submission

- Rigorous peer review

- Open access: articles freely available online

- High visibility within the field

- Retaining the copyright to your article

Submit your next manuscript at springeropen.com 